\title{
Interleaved 4-Phases DC/DC Converter for Electric Scooter to Improve Efficiency
}

\author{
Khairul Nisak Md Hasan ${ }^{1, *}$, Aida Syafiqah Ahmad ${ }^{2}$ and Zainul Azhar Zakaria ${ }^{3}$ \\ ${ }^{1,2}$ Elect \& Electronics Eng., Uni Teknologi PETRONAS, 31260 Seri Iskandar, Perak, Malaysia \\ ${ }^{3}$ Universiti Kuala Lumpur, Malaysian Institute of Marine Eng. Technology, Lumut, Perak, Malaysia
}

\begin{abstract}
This paper presents the design of an Interleaved DC/DC Boost Converter for the implementation of an Electric Scooter. The output of the power converter can be controlled using the Pulse Width Modulation (PWM) switching technique to boost $12 \mathrm{~V}$ battery supply to power a $24 \mathrm{~V}$ Brushed DC Motor with improved efficiency compared to conventional converters. The design of the power converter was calculated for different number of interleaving phases. The simulation is carried out using MATLAB/Simulink for 2, 3, 4, 6 and 8-phases interleaved converters to compare their performances. The 4-phase is selected due to its advantage and further implemented in the prototype. PWM output switching frequency is set to $25 \mathrm{kHz}$ with 4 signals of $90^{\circ}$ phase shift to each other. The testing on a complete prototype was carried out.
\end{abstract}

\section{Introduction}

Conventional vehicles had always been the major cause responsible for the environmental issue. The emissions of hazardous gases into the atmosphere such as the carbon dioxide, carbon monoxide and nitrogen dioxide from the vehicles are the major contributor to the air pollution. Besides, the reduction of the petroleum resources adds to this worrying problem. Hence, Electric Vehicle has been identified of having potential to replace the conventional vehicles as it promises eco-friendly system with less hazardous gases emissions along with providing significant performance improvement and flexibility compared to the conventional vehicles. A power converter with the interleaving technique is proposed to be part of the Electric Scooter electronics system as preceding studies proved its advantages of reducing voltage input/output ripples, minimize power loss to provide higher efficiency as well as decreasing the weight and size of the passive components of the converter. Common limitation to power operating devices is the energy supply such as the typical Electric Vehicle facing the problem of limited travel distance per full charge of the equipped battery pack. This is a major factor why an electric vehicle is not preferred compared to the conventional vehicles. Energy cannot be created or destroyed but it can be transferred. The power consumption need to be wisely managed to maximize the usage of energy. Major problem encountered with a conventional DC/DC converter is its efficiency. This is the effect of high voltage and current input/output ripple caused by the uneven output waveform that were not

*Corresponding author: khairulnisak.hasan@utp.edu.my 
effectively filtered by the inductor and capacitor. The capacitor absorbs the excess voltage during its cycle of charging and discharging to supply whenever the voltage is needed. This will cancel the ripple off to produce a smoother output waveform. Using a technique of interleaving, these major problems can be solved as it helps in reducing voltage and current input/output ripples, minimize power loss to provide higher efficiency as well as decreasing the weight and size of the passive components of the converter.

\section{Interleaving DC/DC Converter}

\subsection{Interleaved DC/DC Converter in Electric Vehicles}

A DC/DC power converter is commonly applicable for converting direct current of a source from certain voltage level to another voltage level. Besides, it is also useful in storing excess energy momentarily to be supplied whenever extra energy is needed at different voltage value. This storing can either be conducted by inductors or transformers when using magnetic field storage of by the capacitor when using electric field storage [7]. These processes will help in producing a stable output voltage for achieving high power converter performance and higher efficiency percentage. The output power rating of a converter is designed to fulfil the need of the device or vehicle to be built for example to specially design a converter for the characteristics of Electric Vehicle, the converter need to be suitable for its top speed, weight, top speed, acceleration and torque [7].

Interleaving techniques for converter has been chosen as the preferable power converters for current technology [2]. Advancement in technology always growing towards the significance of performance. This interleaving technique is widely used especially in Hybrid Vehicles and Electric Vehicles as it promises reduction of filter size by raising the effective frequency and significantly clearing voltage and current ripple effects [2]. On top of that, this technique also helps in minimizing the size and weight of the passive components of a power converter to produce a simpler and compact circuit design topology. Despite its compression, the efficiency is significantly increased to a higher percentage as compared to the conventional converter [1]-[3]. Another important change brought by this technique are the replacement of the aluminium electrolyte usage or polymer organic capacitors that capable of improving the total series resistance, reliability in a rough thermal environment as well as power density [2]. The control complexity, cost and weight increase as the number of phases of a converter increases. This makes the optimum number of phases when designing a converter to be limited [2]. For example, a converter with four phases will have two switches and two diodes connected in parallel per phase constructing a total of eight switches and eight diodes. The simplest way of reducing the size of the passive components is by increasing the frequency of the inductor current ripple and output voltage ripple using the technique called phase-shift interleaved control. This control strategy will double up the inductor ripple frequency without changing the switching frequency resulting fast dynamic response which is very crucial in designing high performance power converter [7].

Table 1. Available Interleaved Converters.

\begin{tabular}{|c|c|c|c|}
\hline Phase & Power Output & Mode & Efficiency \\
\hline 2 & $16 \mathrm{~kW}$ & Continuos Conduction & $95 \%$ \\
\hline 16 & $5.1 \mathrm{~kW}$ & Continuos Conduction & $95.3 \%$ \\
\hline 2 & $30 \mathrm{~kW}$ & Continuos Conduction & $97.5 \%$ \\
\hline 2 & $1 \mathrm{~kW}$ & Continuos Conduction & $98 \%$ \\
\hline 4 & $30 \mathrm{~kW}$ & Discontinuos Conduction & $92.5 \%$ \\
\hline
\end{tabular}




\subsection{Topologies of Interleaved 4-phases DC/DC Converter}

The topologies of the Interleaved DC/DC Converter consist of converter with 2, 3, 4, 6 and 8 number of phases being compared to the conventional converter to investigate the performance of each design. This project is aimed to cater the most suitable converter for Electric Scooter application. The converter is primarily designed to boost the supply voltage from Li-ion battery at $12 \mathrm{~V}$ to $24 \mathrm{~V}$ at the load connected to a DC motor. Insulated Gate Bipolar Transistor (IGBT) will be used as the switch in the circuit as it has advantages of high switching frequency, low duty cycle and high current handling capability. Besides, IGBT also has all the advantages of Bipolar Junction Transistor (BJT) and MOSFET.

This proposed circuit of the Bidirectional Interleaved DC/DC Converter are using number of phases $(\mathrm{N})$ connected in parallel. It consists of a number of boost converters connected in parallel controlled by interleaved technique with the same phase shift and frequency. The current flowing through each phase will be $1 / \mathrm{N}$ of the total current flow though the converter resulting the voltage across and the power loss in the switching devices is reduced to significant value. The components used in this topology are IGBT module, inductor, diode and capacitor. Each IGBT has its own anti-paralleled diode which will be carrying current during free-wheeling period. Inductors can act as boost inductors under boost mode operation or low-pass filter inductor under buck mode operation. Besides, as the number of the inductor increases according to the number of phases of this converter, the size for each inductor will be also significantly reduced compared to the standard converter. This configuration will be having $180^{\circ}$ switching angle per phase as the total switching angle is $360^{\circ}[6]$.

\subsection{Circuit Parameters and Simulation}

In order for the designed converter to achieve the required output, the parameters for every component is calculated. The input voltage is $12 \mathrm{~V}$ coming from the battery and the desired output voltage is $24 \mathrm{~V}$ to supply the motor. The relationship between inductor minimum current $I_{\text {min }}$, peak current $I_{\text {peak }}$, inductor RMS current $I_{R M S}$ are being expressed in (3.1) - (3.6). The parameter values for conventional boost converter is tabulated in Table 2 .

Table 2. Parameters of Conventional Boost Converters.

\begin{tabular}{|c|c|c|}
\hline Parameter & Symbol & Value \\
\hline Input Voltage & $\mathrm{V}_{\text {in }}$ & $12 \mathrm{~V}$ \\
\hline Output Voltage & $\mathrm{V}_{\text {out }}$ & $24 \mathrm{~V}$ \\
\hline Resistance $($ load $)$ & $\mathrm{R}_{\mathrm{L}}$ & $100 \Omega$ \\
\hline Capacitance & $\mathrm{C}$ & $47 \mu \mathrm{F}$ \\
\hline Inductance & $\mathrm{L}$ & $2.4 \mathrm{mH}$ \\
\hline Frequency & $\mathrm{T}_{\mathrm{s}}$ & $25 \mathrm{kHz}$ \\
\hline Duty Cycle & $\mathrm{D}$ & 0.55 \\
\hline
\end{tabular}

The interleaved converters are derived from the conventional boost converter by paralleling the switch and inductors. Hence, the value of inductance, $L$, differs for each design depending on the number of phases such that $\mathrm{L}_{1}, \mathrm{~L}_{2}$ until the $\mathrm{L}_{\mathrm{N}}$ is calculated using the formula of $\mathrm{L} / \mathrm{N}$ where $\mathrm{N}$ is the number of phases. For example, the value of L1 and L2 for 2-phases interleaved converter is $2.4 \mathrm{mH} / 2=1.2 \mathrm{mH}$. The values for other parameters such as $\mathrm{R}, \mathrm{C}$, $\mathrm{T}_{\mathrm{s}}, \mathrm{D}$ and $\mathrm{V}_{\text {in }}$ are kept constant to monitor the significant changes in the $\mathrm{I}_{\mathrm{in}}, \mathrm{I}_{\text {out }}$ and the output ripple percentage while the $\mathrm{V}_{\text {out }}$ were kept as closest to $24 \mathrm{~V}$. 
To test the functionality as well as the values of the desired output, the circuit designs of conventional converter and interleaved converters with various number of phases are simulated using the MATLAB Simulink Software. The interleaved converters with 2-phases, 3-phases, 4-phases, 6-phases and 8-phases are simulated to compare the performance. Figure 1 shows the conventional boost converters and Figure 2 and 3 show the 2-phases and 4-phases interleaved converters respectively.

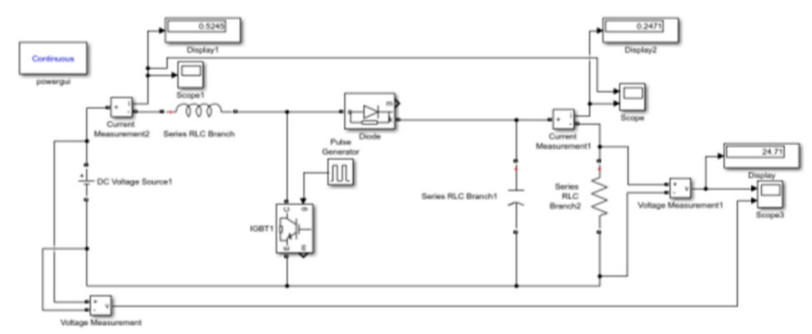

Fig. 1. Conventional boost converters.

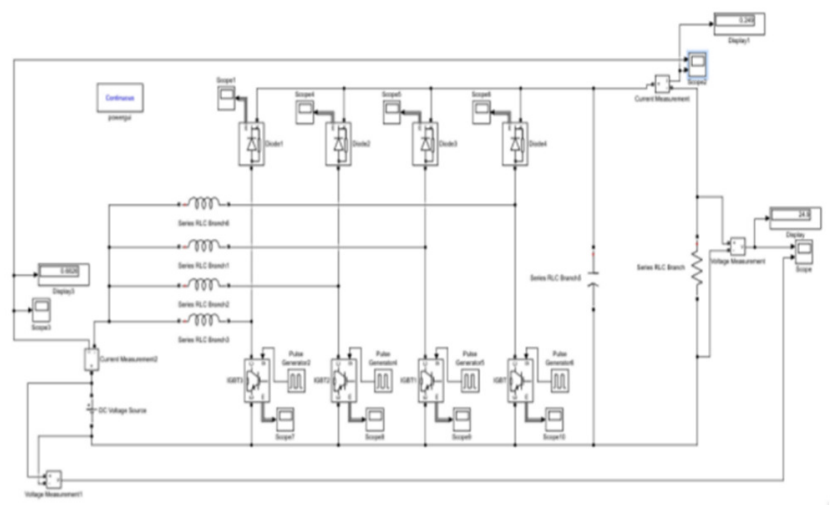

Fig. 2. 4-phases interleaved converters.

The Pulse Width Modulation (PWM) signal is programmed into a controller to trigger the IGBT power switch to implement the interleaved technique for the converter where the power switches will be turned on alternately following the programmed four modulated signal preset with $55 \%$ duty cycle and $25 \mathrm{kHz}$ switching frequency with $90^{\circ}$ phase shift between signals.

\section{Prototype Fabrication}

Based on the simulation result, the 4-phase interleaved converters is chosen. It has the highest efficiency with relatively small inductance. The Interleaved 4-phases DC/DC Converter is fabricated on a Stripboard and the PWM signals is generated by an Arduino UNO as shown in the Figure 4.

\subsection{Electric Scooter Prototype}

A working prototype of an Electric Scooter which was converted from a bicycle has been developed. It uses the chain mechanism with adjusted gear and driven by a 24-V Brushed Direct-Current (BDC) motor with rated current of 22-A. It is equipped with an LCD display to monitor the speed which is measured using reed sensor. The Electric Scooter is also using 
the electronic speed control (ESC) to control the speed at low, medium or highest speed. The $12-\mathrm{V}$ lead-acid battery is used to supply the motor since it able to power-up for a longer duration. The interleaved 4-phases DC/DC Converter module is connected to the battery to supply the 24-V motor. Fig. 4 shows the complete Electric Scooter.

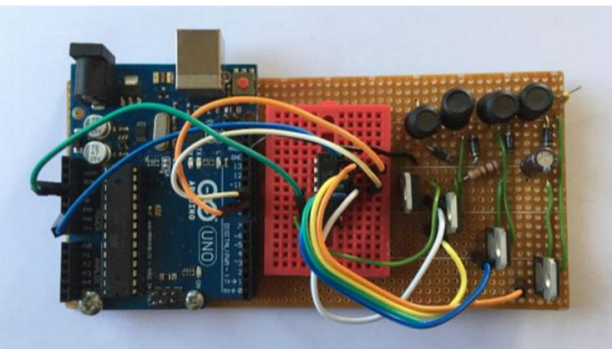

Fig. 3. Interleaved 4-phases DC/DC Converter

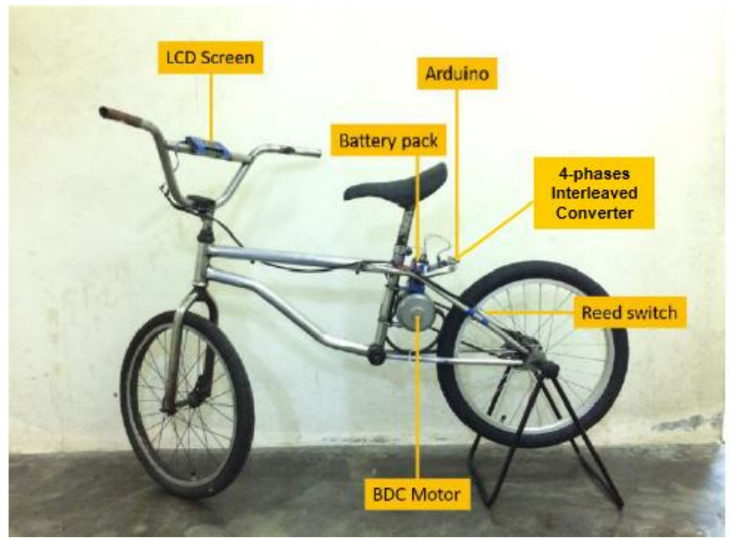

Fig. 4. Complete prototype of Electric Scooter

\subsection{Pulse-Width Modulation (PWM) Generation}

The PWM is generated by using an Arduino UNO. The switching frequency is set to $25 \mathrm{kHz}$ with $50 \%$ Duty Cycle. Two signals of $0^{\circ}$ and $270^{\circ}$ phase shift is generated at the PWM output Pin9 and Pin 10 respectively. For the $90^{\circ}$ and $180^{\circ}$ phase shift signals, the output of Pin9 and Pin 10 are inverted resulting Pin9 inverted to be $180^{\circ}$ and Pin 10 inverted to be $90^{\circ}$. Hence, 4 signals of pulse are being generated with $90^{\circ}$ phase shift between each pulse to control 4 power switches of an Interleaved 4-phases DC/DC Converter.
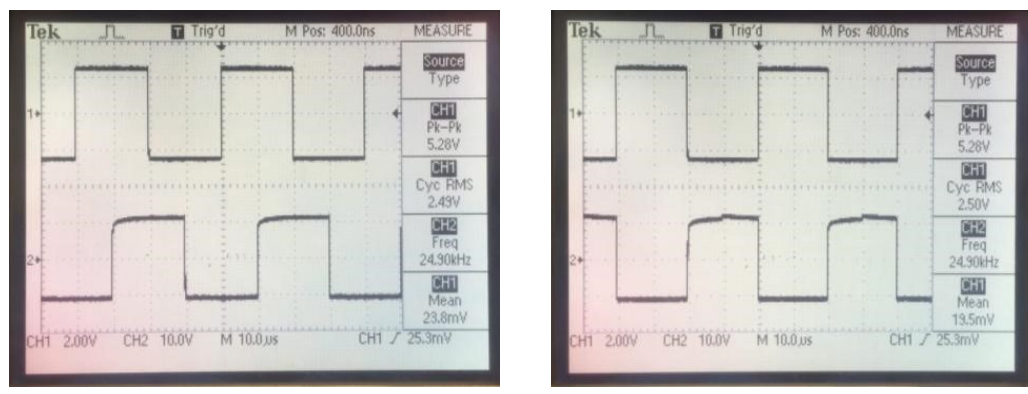

Fig. 5. PWM generated signals with $0^{\circ} \& 90^{\circ}$ phase-shift (left) and $0^{\circ} \& 180^{\circ}$ phase-shift (right) 


\section{Result and Discussions}

The circuit topologies described in section 2.3 were simulated using MATLAB and performance of the converters were analysed. Input DC Voltage are kept constant at $12 \mathrm{~V}$ as well as the parameter value including load resistance, filter capacitance, duty cycle and the switching frequency. Results of voltage and current output waveform of each topology are shown in Figure 5 and 6, and the results of all converters are summarized in Table 3.
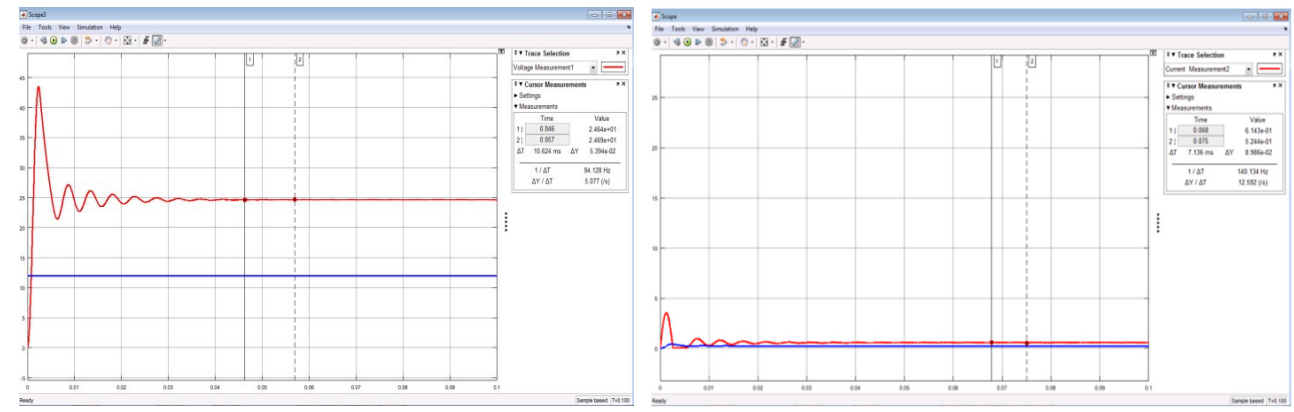

Fig. 5. Voltage (left) and current (right) output of conventional converter
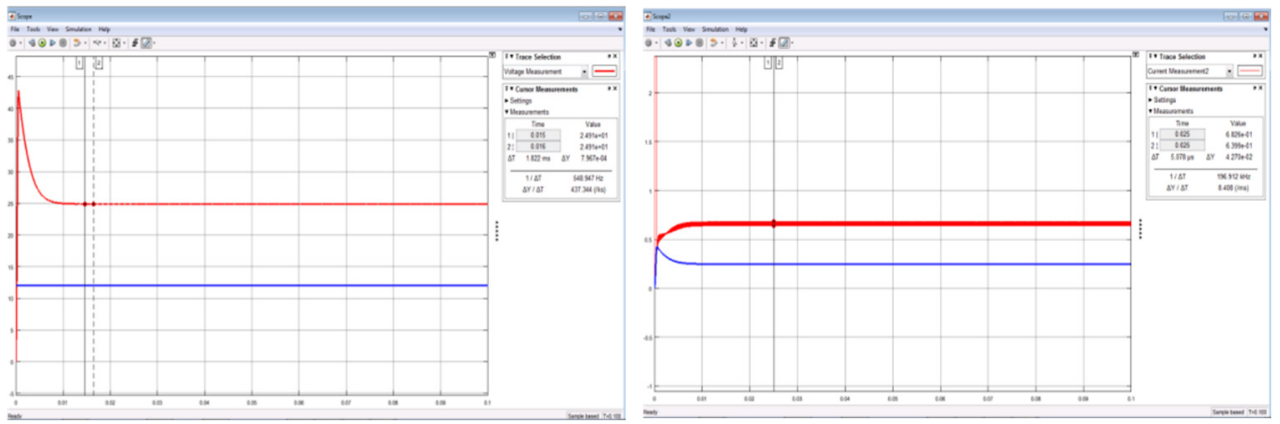

Fig. 6. Voltage (left) and current (right) output of 4-phase Interleaved converter

Table 3. Output Current and Voltage for Conventional (1 phase) and Interleaved Converters.

\begin{tabular}{|c|c|c|c|c|c|c|}
\hline $\begin{array}{c}\text { No. of } \\
\text { phases }\end{array}$ & $\begin{array}{c}\text { Inductor } \\
\text { values }\end{array}$ & \multirow{2}{*}{$\mathbf{I}_{\text {in }}(\mathbf{A})$} & \multirow{2}{*}{$\mathbf{I}_{\text {out }}(\mathbf{A})$} & \multirow{2}{*}{$\mathbf{V}_{\text {out }}(\mathbf{V})$} & \multicolumn{2}{|c|}{ Output Ripple (\%) } \\
\cline { 6 - 7 } & & & & $\mathbf{V}$ & $\mathbf{I}$ \\
\hline 1 & $2.4 \mathrm{mH}$ X 1 & 0.5245 & 0.2471 & 24.71 & 0.20 & 36.38 \\
\hline 2 & $1.2 \mathrm{mH} \mathrm{X} \mathrm{2}$ & 0.5835 & 0.2465 & 24.65 & 0.08 & 11.93 \\
\hline 3 & $0.8 \mathrm{mH} \mathrm{X} \mathrm{3}$ & 0.5826 & 0.2465 & 24.65 & 0.04 & 36.67 \\
\hline 4 & $0.6 \mathrm{mH} \mathrm{X} \mathrm{4}$ & 0.6826 & 0.2490 & 24.90 & 0.04 & 16.31 \\
\hline 6 & $1.0 \mathrm{mH} \mathrm{X} \mathrm{6}$ & 0.6126 & 0.2474 & 24.74 & 0.08 & 84.80 \\
\hline 8 & $1.5 \mathrm{mH} \mathrm{X} \mathrm{8}$ & 0.7630 & 0.2481 & 24.81 & 0.00 & 3.43 \\
\hline
\end{tabular}

It can be clearly seen that the performance of a converter improves with the implementation on interleaved technique. The comparison is between the conventional (1phase) and interleaved converter (2-phases) with the data tabulated in the table. The current measured at the input of the inductor for interleaved converter is $0.5835 \mathrm{~A}$ compared to $0.5245 \mathrm{~A}$ for a conventional converter. Besides, the voltage output ripple is significantly reduced with the implementation of interleaving technique from $0.2 \%$ to only $0.08 \%$ while current output ripple is reduced from $36.38 \%$ to $11.93 \%$. From the tabulated data in Table 6 , the best result 
is being shown by the output given by the 8-phases interleaved converter with the ability to supply the highest input current as well as producing a great output ripple cancellation for voltage and current ripple reduction that almost negligible with the value of only $3.43 \%$. However, the circuit fabricated is the 4-phases Interleaved DC/DC Converter as the 8-phases converter will be too complex with 8 sets of inductors, power switches and PWM signals. Besides, the 8-phases converter shows that the inductor values required to produce $24 \mathrm{~V}$ is $1.5 \mathrm{mH}$ which an increment value with unproportioned to the increment of the number of phase which supposed to be $0.3 \mathrm{mH}$ for each inductor as calculated using formula of total inductance divided by the number of phase. Hence, one of the objective of this project which is to propose the most effective and simple Interleaved DC/DC Converter resulting the 4phases converter is chosen over 8-phases converter with the acceptable voltage input/output ripples of only $0.04 \%$.

\section{Conclusion}

As a conclusion, there are many aspects need to be taken into consideration for designing a converter for an Electric Scooter. Different topologies will have different goal such as the efficiency, output power and dynamic response. A good power converter is aimed to achieve good performance in all aspects thus need a deep understanding in designing one. For this project, a 4-phases DC/DC Converter with the implementation of interleaving technique is proposed. This type of converter promises the advantages of reducing input/output ripples, minimize switching power loss to provide higher efficiency, offers faster transient response as well as decreasing the size and weight of the passive components of the converter.

\section{References}

1. O. Hegazy, J. V. Mierlo, and P. Lataire, Journal of Power Electronics, 11, no. 4, pp. 408417 (2011)

2. L. Ni, D. J. Patterson, and J. L. Hudgins, IEEE Energy Conversion Congress and Exposition, (2010).

3. O. Hegazy, J. V. Mierlo, and P. Lataire, IEEE Transactions on Power Electronics, vol. 27, no. 11, pp. 4445-4458 (2012)

4. A. M. Omara and M. Sleptsov, 11th International Forum on Strategic Technology, (2016)

5. R. R. Melo, F. L. M. Antunes, and S. Daher, 16th European Conference on Power Electronics and Applications, (2014)

6. S. Kanta, B. Plangklang, and W. Subsingha, Energy Procedia, 56, pp. 604-609, (2014)

7. M. Al, J. Van, and H. Gualous, Electric Vehicles - Modelling and Simulations, (2011)

8. S. Dusmez, A. Hasanzadeh, and A. Khaligh, IEEE Trans. Ind. Electron., vol. 62, no. 5, pp. 3305-3315, (2015)

9. S.-Y. Hsu, J.-C. Li, C.-M. Lu, C.-H. Lin, and C.-M. Wang, IET Power Electron., vol. 7, no. 9, pp. 2437-2445, (2014)

10. S. Grunau, M. Fox, and F. W. Fuchs, 15th EPE-PEMC 2012 ECCE Eur., pp. 1-8, (2012)

11. A. Thiyagarajan, S. G. P. Kumar, and A. Nandini, International Conference on Current Trends In Engineering and Technology, (2014)

12. Ritu, N. Verma, S. Mishra, and S. Shukla, Communication, Control and Intelligent Systems, (2015) 